\title{
Modelagem do controle climático nas taxas de erosão mecânica e de intemperismo químico na bacia do Rio Sorocaba (SP)
}

Alexandre Martins Fernandes ${ }^{1 *}$ Fabiano Tomazini da Conceição ${ }^{1}$ Eder Paulo Spatti Junior ${ }^{1}$ Antonio Aparecido Couto Junior ${ }^{1}$ Jefferson Mortatti ${ }^{2}$

${ }^{1}$ Instituto de Geociências e Ciências Exatas Universidade Estadual Paulista "Júlio de Mesquita Filho"

Avenida 24, 1515

Caixa Postal 178

Rio Claro, SP, Brasil

CEP 13506-900

Tel: +55 1935269358

${ }^{2}$ Centro de Energia Nuclear na Agricultura Universidade de São Paulo

Avenida Centenário, 303

Caixa Postal 96

Piracicaba, SP, Brasil.

CEP: $13416-970$

Tel: +55 1934294673

Autor correspondente

alefernandes1966@yahoo.com.br

\section{RESUMO}

A influência do controle climático sobre as taxas de remoção de solos e de intemperismo químico na bacia do Rio Sorocaba, SP, foi avaliada a partir da caracterização físico-química das águas fluviais e da quantificação das concentrações e fluxos fluviais de TSS e TDS em dois pontos de amostragem (S1 e S2) no período de jun/2009 a jun/2010. Foram estabelecidos 12 cenários baseados na variação das vazões ao longo do período de estudo, associando as respectivas concentrações de TSS, TDS, $\mathrm{SiO}_{2}$ e cátions dissolvidos. Os fluxos fluviais corrigidos dos aportes atmosféricos e antrópicos calculados para S1 e S2 permitiram determinar as taxas de remoção de solos $\left(\mathrm{W}_{\mathrm{M}}\right)$ e de intemperismo químico das rochas $\left(\mathrm{W}_{\mathrm{Ch}}\right)$ na Bacia do Rio Sorocaba, ou seja, 49,5 e 9,6 m/Ma em S1 e de 12,8 e 7,6 m/Ma em S2, respectivamente. O balanço entre estas taxas evidenciou uma maior remoção de solos em $\mathrm{S} 1\left(\mathrm{~W}_{\mathrm{M}} \approx 5,2 \mathrm{~W}_{\mathrm{Ch}}\right)$, em comparação à $\mathrm{S} 2\left(\mathrm{~W}_{\mathrm{M}} \approx 1,7\right.$ $\mathrm{W}_{\mathrm{Ch}}$ ). $\mathrm{O}$ processo de intemperismo químico de rochas avaliado pelo índice $\mathrm{R}_{\mathrm{E}}$ indicou tendência para o domínio da monossialitização. Os cenários propostos corroboraram a influência do clima nos processos intempéricos, com predomínio dos processos de intemperismo químico das rochas nos cenários relacionados às condições climáticas de baixa pluviosidade e temperaturas mais amenas, e o predomínio dos processos de remoção dos solos em condições mais chuvosas e temperaturas mais elevadas.

Palavras-chave: modelagem de sistemas naturais, geoquímica fluvial, bacia hidrográfica, influências antrópicas.

\section{ABSTRACT}

The influence of climate control on soil removal and chemical weathering rates in the Sorocaba River Basin, SP, was evaluated through the physicochemical characterization of the fluvial waters and the quantification of TSS and TDS concentrations and fluvial fluxes at two sampling points (S1 and S2) from June 2009 to June 2010. Based on the discharge variation over the study period, 12 scenarios were established with the respective concentrations of TSS, TDS, $\mathrm{SiO}_{2}$ and dissolved cations. After correction of the atmospheric and anthropogenic inputs, were determined the rates of soil removal $\left(\mathrm{W}_{\mathrm{M}}\right)$ and chemical weathering of the rocks $\left(\mathrm{W}_{\mathrm{Ch}}\right)$ in the Sorocaba River Basin, i.e., 49.5 and $9.6 \mathrm{~m} / \mathrm{Ma}$ at $\mathrm{S} 1$ and 12.8 and $7.6 \mathrm{~m} / \mathrm{Ma}$ at $\mathrm{S} 2$, respectively. The balance between these rates showed a higher soil removal in $\mathrm{S} 1\left(\mathrm{~W}_{\mathrm{M}} \approx 5.2\right.$ $\left.\mathrm{W}_{\mathrm{Ch}}\right)$ compared to $\mathrm{S} 2\left(\mathrm{~W}_{\mathrm{M}} \approx 1,7 \mathrm{~W}_{\mathrm{Ch}}\right)$. Evaluated through the $\mathrm{R}_{\mathrm{E}}$ index, the chemical weathering indicated a tendency to towards the monosialitization domain. The proposed scenarios corroborated the climate influence, with predominance of chemical weathering of the rocks processes under low rainfall and milder temperatures, and the predominance of soil removal processes in warm and rainy climatic conditions.

Keywords: natural systems modeling, fluvial geochemistry, watershed, anthropogenic influences. 


\section{INTRODUÇÃO}

Os cursos de água refletem a dinâmica dos processos que ocorrem em sua área de drenagem, compreendendo tanto seus atributos físicos, químicos e biológicos quanto a inter-relação de seus vários componentes, como solo, água, cobertura vegetal e atmosfera (Jenkins et al. 1994, Mortatti \& Probst 2003). Estudos sobre a hidroquímica fluvial utilizam diferentes metodologias associadas ao controle físicoquímico das águas e ao transporte fluvial de material em suspensão visando compreender os parâmetros que configuram e controlam a alteração das rochas e a denudação do solo, bem como para avaliar as possíveis alterações naturais e influências antrópicas que ocorrem em uma área de drenagem. A determinação das taxas de intemperismo químico e erosão física dos solos é de interesse dos geocientistas, pois fornecem parâmetros para uma melhor compreensão e modelagem geomorfológica da Terra.

Diversos trabalhos foram desenvolvidos a partir dos anos 1960-70 visando investigar a natureza e composição da matéria transportada pelos rios, como a quantificação das cargas dissolvidas e em suspensão que chegam aos oceanos (ex. Barth 1961, Gibbs 1970) e a determinação das taxas de alteração de rochas e de remoção de solos em bacias de drenagem (ex. Tardy 1971, Mortatti et al. 1992, Gaillardet et al. 1997, Mortatti et al. 1997, Boeglin \& Probst 1998, Semhi et al. 2000, Bortoletto Junior et al. 2002, Mortatti \& Probst 2003, Conceição \& Bonotto 2003 2004, Weijden \& Pacheco 2006, Li \& Zhang

\section{2. ÁREA DE ESTUDO}

A bacia do Rio Sorocaba foi adotada como área de estudo por apresentar uma condição climática bem definida, tipo Cwa segundo a classificação Köppen (IPT 2006), i.e. quente e úmido no verão e seco no inverno, com temperatura média anual variando entre $18 \mathrm{e}$ $22^{\circ} \mathrm{C}$. As médias mensais e anuais de precipitação e vazão para o período de 1959 a 2008 (Figura 1A), obtidas junto ao DAEE (2010) para a estação pluviométrica E4-019 Iperó $\left(23^{\circ} 20^{\prime} \mathrm{S}, 47^{\circ} 41^{\prime} \mathrm{W}\right)$, localizada na região central da bacia de drenagem, e estação fluviométrica 4E-001 Entre Rios $\left(23^{\circ} 01^{\prime} \mathrm{S}, 47^{\circ} 48^{\prime} \mathrm{W}\right)$, localizada junto à foz do Rio Sorocaba no município de Laranjal Paulista, corroboraram esta sazonalidade. As médias anuais de precipitação e vazão para esse período de 50 anos foram de $1219 \mathrm{~mm}$ e $59,8 \mathrm{~m}^{3} / \mathrm{s}$, respectivamente, sendo janeiro o mês mais chuvoso (média de $215 \mathrm{~mm}$ ) e agosto o mais seco
2008, Mortatti et al. 2008, Sardinha et al. 2010, Conceição et al. 2010, Gurumurthy et al. 2012, Edet et al. 2013, Laraque et al. 2013, Li et al. 2014; Conceição et al., 2015; Fernandes et al. 2016a 2016b). Destacam-se também os estudos que utilizam coleções de dados publicados para estimar processos globais de intemperismo (Martin \& Meybeck 1979, Meybeck 1987, White \& Blum 1995, Gaillardet et al. 1999, Meybeck et al. 2003, Walling \& Fang 2003) e os que avaliam como esses processos são controlados por fatores como litologia, relevo e clima, entre outros (Paces 1986, Lasaga et al. 1994, Harrison 2000, Dupré et al. 2003, Oliva et al. 2003, Riebe et al. 2004, Velbel \& Price 2007). Apesar da extensa literatura disponível, são poucos os trabalhos que procuram modelar a influência climática nos processos de intemperismo que ocorrem em uma determinada bacia de drenagem, como por exemplo, o realizado por Spatti Junior et al. (2014).

O presente trabalho teve por objetivo avaliar os processos de remoção de solos e de intemperismo químico das rochas por meio da dinâmica do transporte fluvial do total de sólidos em suspensão e da carga dissolvida de $\mathrm{Na}^{+}, \mathrm{Ca}^{2+}, \mathrm{K}^{+}, \mathrm{Mg}^{2+}$ e $\mathrm{SiO}_{2}$, estimando-se os fluxos e taxas relacionados a esses processos em uma bacia de drenagem tropical na América do Sul, mais especificamente a bacia do Rio Sorocaba, e verificar qual seria o comportamento desses fluxos e taxas diante de possíveis alterações climáticas considerando 12 cenários distintos baseados na sazonalidade da vazão ao longo de um ciclo hidrológico.

(média de $32 \mathrm{~mm}$ ), enquanto que a maior vazão média ocorreu no mês de fevereiro $\left(107,1 \mathrm{~m}^{3} / \mathrm{s}\right)$ e a menor em agosto $\left(35,5 \mathrm{~m}^{3} / \mathrm{s}\right)$. Nesse mesmo período a correlação entre a vazão média mensal e a precipitação média mensal mostrou-se positiva e significativa (Figura 1B).

Localizado na região sudeste do Estado de São Paulo, Brasil, entre as latitudes $23^{\circ}$ e $24^{\circ} \mathrm{S}$ e longitudes $47^{\circ}$ e $48^{\circ} \mathrm{W}$ (Figura 2), o Rio Sorocaba percorre $227 \mathrm{~km}$ em direção noroeste até sua confluência com o Rio Tietê, sendo considerado o afluente mais importante da margem esquerda da bacia do Médio Tietê. Sua área de drenagem ocupa $5.269 \mathrm{~km}^{2}$, e abrange 18 municípios, com uma população total de aproximadamente 1,2 milhões de habitantes e um parque industrial diversificado composto por mais de 1850 empreendimentos (IPT 2006, IBGE 2010). 
A

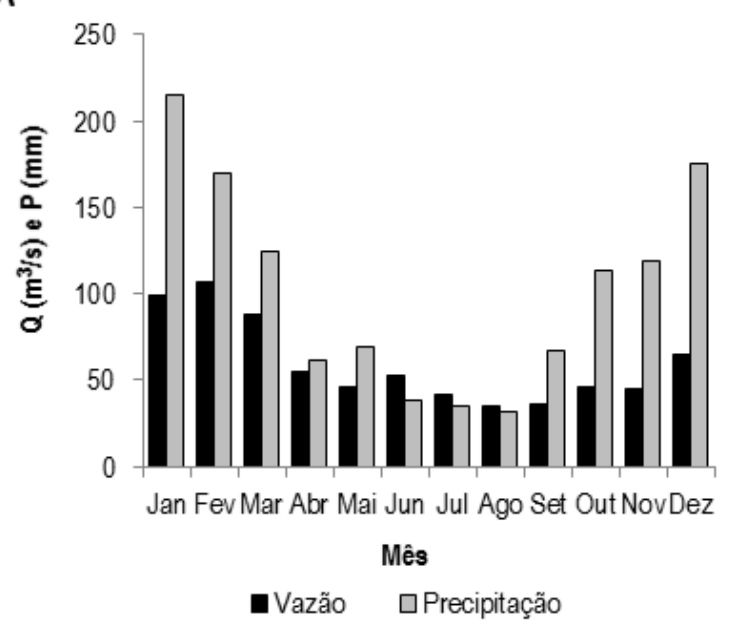

B

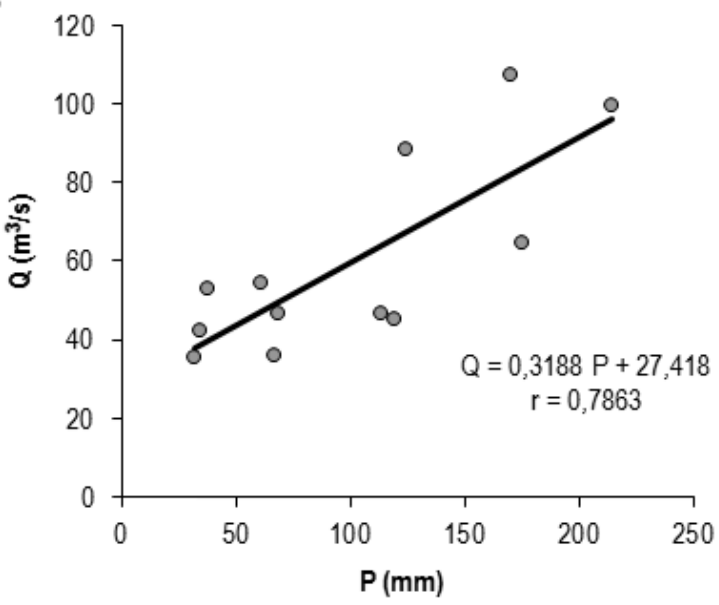

Figura 1

Médias mensais de Vazão (Q) e Precipitação $(P)(A)$ e relação $P \times Q(B)$ para a bacia do Rio Sorocaba no período de $1959-2008$.

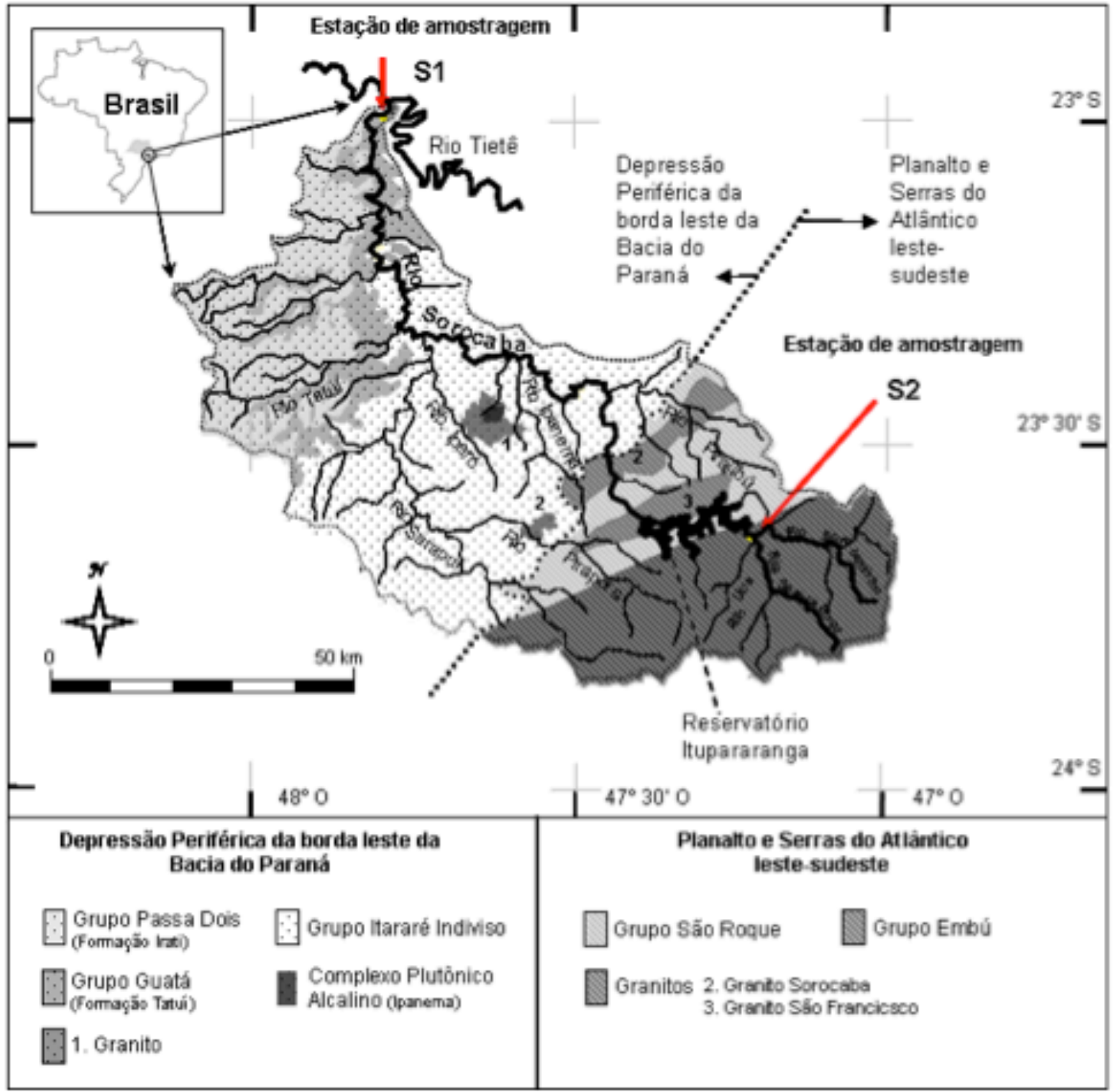

Figura 2

Bacia do Rio Sorocaba, com suas principais unidades litoestratigráficas e a localização das estações de amostragem S1, no município de Laranjal Paulista, e S2, no município de Ibiúna. 
A bacia do Rio Sorocaba está inserida em duas unidades geomorfológicas distintas. A primeira, Planaltos e Serras do Atlântico leste sudeste, na região do Alto Sorocaba, é representada por rochas de baixo grau metamórfico do Grupo São Roque e paragnaisses e migmatitos do Complexo Embú e seus granitos associados, e apresenta um modelado dominante constituído por morros com formas convexas e vales profundos, com altitudes entre 800 e 1000 metros e declividades acima de $20 \%$, caracterizando-se uma elevada densidade de drenagem. A segunda, Depressão Periférica da borda leste da Bacia do Paraná, é representada por rochas da Bacia Sedimentar do Paraná de diferentes ciclos deposicionais, constituídas predominantemente por arenitos, siltitos e argilitos, estando o médio curso do Rio Sorocaba sob o domínio do Grupo Itararé, enquanto que o baixo curso encontra-se nos Grupos Guatá e Passa Dois. O relevo nesta segunda unidade é

\section{MATERIAL E MÉTODOS}

Foram realizadas 12 coletas de amostras de águas fluviais no período de jun/2009 a jun/2010 em dois pontos de amostragem. O primeiro, denominado S1, correspondeu ao exutório da bacia do Rio Sorocaba, localizada no município de Laranjal Paulista (Lat. 2303'53”'S, Long. $47^{\circ} 49^{\prime} 13^{\prime} \mathrm{W}$ ), integrando o escoamento total de uma área de drenagem de $5.269 \mathrm{~km}^{2}$. O segundo, denominado $\mathrm{S} 2$, localizou-se no município de

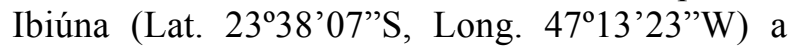
jusante da confluência dos Rios Sorocamirim e Sorocabuçu, formadores do Rio Sorocaba, e correspondeu a uma área de drenagem de 680 $\mathrm{km}^{2}$, toda ela na unidade Planaltos e Serras do Atlântico leste sudeste.

A cada coleta foram amostrados $500 \mathrm{~mL}$ de águas fluviais nas margens esquerda e direita do rio e no eixo principal da corrente, sempre a $1,5 \mathrm{~m}$ de profundidade, utilizando um amostrador pontual de estágio simples, compostas por ponto de amostragem $(1500 \mathrm{~mL})$ e separadas em duas alíquotas de $500 \mathrm{~mL}$, uma bruta e outra preservada com $0,1 \mathrm{~mL}$ de $\mathrm{H}_{2} \mathrm{SO}_{4}$ concentrado, ambas armazenadas em frascos de polietileno identificados e mantidas sob refrigeração a $4^{\circ} \mathrm{C}$ até processamento em laboratório. $\mathrm{O}$ volume excedente foi descartado. Também foi

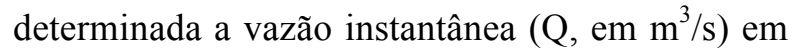
cada ponto de amostragem, resultado do produto entre a área úmida da seção transversal do canal fluvial, obtida por batimetria, e a velocidade média do fluxo de água nessa seção, calculada com os valores observados a $20 \%$ e $60 \%$ da profundidade do rio nas margens esquerda e constituído basicamente por colinas de topos amplos tabulares e convexos, com altitudes entre 600 e $700 \mathrm{~m}$ e declividades variando entre 5 e 10\% (Ross 1996, Ross \& Moroz 1997)

Os solos predominantes na bacia de drenagem são o Argissolo Vermelho (49\%) e o Latossolo Vermelho (38\%), com importantes manchas de Latossolo Vermelho-Amarelo (9\%), concentradas na região do Planalto Atlântico (Oliveira et al. 1999). A maior parte da vegetação original da bacia do Rio Sorocaba, caracterizada por matas, capoeiras, campos, cerrados e vegetação de várzea, foi retirada e substituída pela ocupação agrícola e pelos processos de urbanização, sendo que o uso e ocupação da terra na bacia de drenagem apresenta um predomínio de pastagens e campos antrópicos $(77 \%)$, seguido pelas áreas com culturas agrícolas (14\%), de reflorestamento $(3 \%)$, de remanescentes de cobertura vegetal natural (2\%) e áreas urbanas (4\%) (IPT 2006).

direita e no eixo da corrente utilizando um Micromolinete Digital Global Water FP 101. Os parâmetros $\mathrm{pH}$, condutividade elétrica (CE) e temperatura $(\mathrm{T})$ foram obtidos em campo utilizando os equipamentos portáteis Digimed DM2 (pH) e Digimed DM4 (CE e T).

Nas amostras de água bruta, após filtragem em membrana de acetato de celulose $(0,45 \mu \mathrm{m})$, foram quantificadas $\left[\mathrm{Ca}^{2+}\right],\left[\mathrm{Mg}^{2+}\right],\left[\mathrm{Na}^{+}\right]$e $\left[\mathrm{K}^{+}\right]$ por cromatografia iônica, utilizando um cromatógrafo Dionex ICS-90 equipado com coluna IonPac ${ }^{\circledR}$ CS12A 4x250 mm Analytical, com limites de deteç̧ão de $0,001 \mathrm{mg} / \mathrm{L}$ (Dionex Corporation 2004) e de quantificação de 0,01 $\mathrm{mg} / \mathrm{L}$ (Ribani et al. 2004). As amostras preservadas com $\mathrm{H}_{2} \mathrm{SO}_{4}$ concentrado foram filtradas em membrana de fibra de vidro $(0,3-0,6$ $\mu \mathrm{m})$ e utilizadas na determinação de [Si] utilizando um ICP-OES Optima 3000 DV com limite de detecção de $0,02 \mathrm{mg} / \mathrm{L}$, sendo o resultado expresso em termos de $\mathrm{SiO}_{2}$. O total de sólidos em suspensão (TSS) foi quantificado por metodologia gravimétrica (APHA 1999), considerando o material retido no filtro de acetato de celulose. As concentrações médias anuais de $\mathrm{Ca}^{2+}, \mathrm{Mg}^{2+}, \mathrm{Na}^{+}, \mathrm{K}^{+}, \mathrm{SiO}_{2}$ e TSS foram normalizadas pela vazão, de acordo com a Equação 1 (Probst 1992) e os respectivos fluxos específicos anuais foram quantificados utilizando a metodologia estocástica (Probst et al. 1992), conforme Equação 2.

$$
C_{M N Q}=\frac{\sum_{i=1}^{n} C_{i} \cdot Q_{i}}{\sum_{i=1}^{n} Q_{i}}
$$




$$
F_{E}=\frac{C_{M N Q} \times \bar{Q} \times f}{A}
$$

onde $C_{M N Q}$ é a concentração média normalizada pela vazão $(\mathrm{mg} / \mathrm{L}), C_{i}$ a concentração do íon na iésima amostra $(\mathrm{mg} / \mathrm{L}), Q_{i}$ a vazão instantânea medida no dia de coleta da i-ésima amostra $\left(\mathrm{m}^{3} / \mathrm{s}\right)$,

\section{RESULTADOS E DISCUSSÃO}

\subsection{HIDROQUÍMICA FLUVIAL}

A Tabela 1 apresenta os resultados de vazão e dos parâmetros físicos e químicos obtidos para as águas do Rio Sorocaba nos dois pontos de amostragem durante o período de estudo. A
$F_{E}$ o fluxo específico anual $\left(\mathrm{t} /\left(\mathrm{km}^{2} \mathrm{a}\right)\right), \bar{Q}$ a vazão média do período estudado $\left(\mathrm{m}^{3} / \mathrm{s}\right), f$ corresponde ao fator de correção da massa e do tempo no cálculo do transporte, sendo igual a 31,536 para resultados em t/a, e $A$ a área de contribuição a montante do ponto de amostragem.

Tabela 1 - Vazão e parâmetros físicos e químicos das águas do Rio Sorocaba nos pontos de amostragem S1 e S2 durante o período de estudo, com respectivas médias e desvio-padrão.

\begin{tabular}{|c|c|c|c|c|c|c|c|c|c|c|c|}
\hline \multicolumn{12}{|c|}{ S1 } \\
\hline \multirow{2}{*}{$\begin{array}{c}\text { Data de } \\
\text { amostragem }\end{array}$} & \multirow{2}{*}{$\begin{array}{c}\mathbf{Q}^{(\mathbf{a})} \\
\left(\mathbf{m}^{3} / \mathbf{s}\right)\end{array}$} & \multirow[t]{2}{*}{ pH } & \multirow{2}{*}{$\begin{array}{l}T^{(\mathbf{b})} \\
\left({ }^{0} \mathrm{C}\right)\end{array}$} & \multirow{2}{*}{$\begin{array}{c}\mathrm{CE}^{(\mathrm{c})} \\
(\mu \mathrm{S} / \mathrm{cm})\end{array}$} & $\mathrm{SiO}_{2}$ & $\mathrm{Na}^{+}$ & $\mathbf{K}^{+}$ & $\mathrm{Ca}^{2+}$ & $\mathrm{Mg}^{2+}$ & TDS $^{(d)}$ & $\mathbf{T S S}^{(\mathrm{e})}$ \\
\hline & & & & & \multicolumn{7}{|c|}{$(\mathrm{mg} / \mathrm{L})$} \\
\hline jun/2009 & 37,47 & 6,9 & 15,6 & 143,20 & 35,90 & 27,18 & 1,82 & 16,87 & 1,52 & 169,11 & 14,33 \\
\hline jul/2009 & 43,71 & 6,9 & 16,9 & 123,90 & 31,00 & 23,67 & 1,70 & 16,36 & 1,47 & 150,95 & 46,50 \\
\hline ago/2009 & 123,23 & 6,9 & 16,9 & 109,00 & 14,12 & 10,61 & 1,45 & 11,75 & 1,08 & 90,09 & 54,33 \\
\hline set/2009 & 99,84 & 7,1 & 20,3 & 121,80 & 17,50 & 11,16 & 1,47 & 13,54 & 1,05 & 104,29 & 45,33 \\
\hline nov/2009 & 170,01 & 6,9 & 26,4 & 108,10 & 11,89 & 10,20 & 1,40 & 10,80 & 1,00 & 86,06 & 145,00 \\
\hline $\mathrm{dez} / 2009$ & 363,35 & 6,9 & 25,7 & 76,00 & 10,43 & 5,70 & 1,00 & 8,40 & 0,84 & 63,12 & 87,17 \\
\hline $\mathrm{jan} / 2010$ & 366,47 & 7,1 & 33,0 & 79,70 & 10,44 & 6,03 & 1,10 & 8,50 & 0,82 & 66,35 & 101,50 \\
\hline fev/2010 & 184,04 & 7,1 & 29,0 & 99,60 & 12,45 & 7,70 & 1,70 & 10,50 & 1,20 & 85,94 & 37,83 \\
\hline $\mathrm{mar} / 2010$ & 151,30 & 7,3 & 26,0 & 87,10 & 11,49 & 7,70 & 1,70 & 11,11 & 1,25 & 80,25 & 178,00 \\
\hline $\mathrm{abr} / 2010$ & 107,64 & 7,1 & 25,7 & 103,60 & 12,21 & 9,14 & 1,80 & 13,35 & 1,30 & 96,24 & 51,00 \\
\hline $\mathrm{mai} / 2010$ & 70,21 & 7,1 & 22,2 & 128,60 & 22,00 & 14,92 & 1,90 & 13,26 & 1,40 & 120,61 & 22,67 \\
\hline jun/2010 & 42,15 & 7,3 & 21,1 & 149,10 & 29,00 & 18,83 & 2,10 & 13,69 & 1,90 & 144,94 & 14,50 \\
\hline Média ${ }^{(f)}$ & 146,62 & 7,0 & 23,2 & 110,81 & 13,60 & 9,04 & 1,40 & 10,63 & 1,06 & 84,81 & 84,63 \\
\hline$D^{(g)}$ & 113,13 & 0,2 & 5,3 & 23,46 & 0,14 & 0,11 & 0,01 & 0,05 & 0,01 & 0,58 & 1,07 \\
\hline \multicolumn{12}{|c|}{ S2 } \\
\hline $\begin{array}{c}\text { Data de } \\
\text { amostragem }\end{array}$ & $\begin{array}{c}\mathbf{Q}^{(\mathbf{a})} \\
\left(\mathbf{m}^{3} / \mathbf{s}\right)\end{array}$ & pH & $\begin{array}{l}T^{(b)} \\
\left({ }^{0} \mathrm{C}\right) \\
\end{array}$ & $\begin{array}{c}\mathbf{C E}^{(\mathbf{c})} \\
(\mu \mathrm{S} / \mathbf{c m}) \\
\end{array}$ & $\mathrm{SiO}_{2}$ & $\mathrm{Na}^{+}$ & $\mathbf{K}^{+}$ & $\begin{array}{l}\mathrm{Ca}^{2+} \\
(\mathrm{mg} / \mathrm{L})\end{array}$ & $\mathbf{M g}^{2+}$ & $\operatorname{TDS}^{(d)}$ & TSS $^{(\mathrm{e})}$ \\
\hline jun/2009 & 5,79 & 6,5 & 14,3 & 90,00 & 15,00 & 11,55 & 1,95 & 11,00 & 1,70 & 107,80 & 11,17 \\
\hline $\mathrm{jul} / 2009$ & 6,76 & 6,7 & 14,2 & 90,70 & 12,00 & 10,54 & 2,09 & 10,00 & 1,61 & 91,82 & 9,50 \\
\hline ago/2009 & 19,20 & 6,5 & 14,9 & 71,30 & 10,03 & 6,90 & 1,50 & 7,10 & 1,40 & 63,67 & 13,33 \\
\hline set/2009 & 15,54 & 6,5 & 16,6 & 85,00 & 10,54 & 7,32 & 1,66 & 8,00 & 1,50 & 70,64 & 21,67 \\
\hline nov/2009 & 26,51 & 6,3 & 23,2 & 71,60 & 8,95 & 6,80 & 1,53 & 7,00 & 1,30 & 63,64 & 28,17 \\
\hline $\operatorname{dez} / 2009$ & 56,75 & 6,4 & 22,0 & 64,80 & 7,23 & 5,80 & 1,41 & 6,18 & 1,34 & 54,39 & 23,50 \\
\hline $\mathrm{jan} / 2010$ & 57,24 & 6,5 & 24,3 & 57,90 & 6,70 & 6,06 & 1,35 & 6,20 & 1,35 & 55,33 & 25,00 \\
\hline fev/2010 & 28,71 & 6,4 & 22,0 & 87,80 & 9,17 & 6,46 & 1,70 & 8,20 & 1,40 & 66,99 & 21,50 \\
\hline $\mathrm{mar} / 2010$ & 23,59 & 6,4 & 24,0 & 72,00 & 8,08 & 7,16 & 1,80 & 9,22 & 1,60 & 69,96 & 20,83 \\
\hline $\mathrm{abr} / 2010$ & 16,76 & 6,5 & 22,9 & 72,90 & 8,63 & 6,69 & 1,90 & 9,01 & 1,65 & 73,54 & 10,33 \\
\hline $\mathrm{mai} / 2010$ & 10,91 & 6,6 & 19,1 & 74,90 & 9,08 & 8,62 & 2,10 & 8,00 & 1,75 & 77,95 & 9,80 \\
\hline jun/2010 & 6,52 & 6,7 & 17,3 & 74,80 & 10,16 & 8,14 & 2,07 & 9,10 & 1,76 & 88,41 & 15,83 \\
\hline Média $^{(f)}$ & 22,86 & 6,4 & 19,6 & 70,95 & 8,46 & 6,76 & 1,59 & 7,41 & 1,44 & 64,67 & 20,87 \\
\hline $\mathrm{DP}^{(\mathrm{g})}$ & 17,69 & 0,1 & 3,9 & 0,61 & 0,10 & 0,07 & 0,01 & 0,08 & 0,01 & 0,69 & 0,34 \\
\hline
\end{tabular}

${ }^{(\mathrm{a})}$ Vazão, ${ }^{(\mathrm{b})}$ Temperatura, ${ }^{(\mathrm{c})}$ Condutividade Elétrica, ${ }^{(\mathrm{d})}$ Total de Sólidos Dissolvidos (S1 - Fernandes et al. 2017 , S2 - Fernandes et al. 2016b), ${ }^{(e)}$ Total de Sólidos em Suspensão, ${ }^{(\mathrm{f})}$ Concentração média normalizada pela vazão $\left(\mathrm{C}_{\mathrm{MNQ}}\right)$ de $\mathrm{SiO}_{2}$, cátions, TDS e TSS, ${ }^{(\mathrm{g})}$ Desvio Padrão da $\mathrm{C}_{\mathrm{MNQ}}$ de $\mathrm{SiO}_{2}$, cátions, TDS e TSS.

A vazão apresentou variação sazonal marcante nos dois pontos de amostragem, com menores valores no período seco (junho a setembro de 2009 e abril a junho de 2010) e maiores no período chuvoso (out/2009 a mar/ 2010), acompanhando a sazonalidade verificada na concentração do total de sólidos dissolvidos (TDS) durante o período de estudo em S1 foi obtida em Fernandes et al. (2017) e em S2 em Fernandes et al. (2016b). 
neutralidade no ponto de amostragem S1 $(6,9<$ $\mathrm{pH}<7,3)$, e levemente ácidas no ponto $\mathrm{S} 2(6,3<$ $\mathrm{pH}<6,7)$. A CE apresentou variabilidade sazonal expressiva, com mínimos de 76,00 $\mu \mathrm{S} / \mathrm{cm}$ em S1 e $57,90 \mu \mathrm{S} / \mathrm{cm}$ em S2 durante o período chuvoso, e máximos de $149,10 \mu \mathrm{S} / \mathrm{cm}$ em S1 e $90,70 \mu \mathrm{S} / \mathrm{cm}$ em S2, ambas no período seco, sendo que em S1 a média do período estudado mostrou-se acima do limite superior esperado para águas naturais, que é de $100 \mu \mathrm{S} / \mathrm{cm}$ (Hermes \& Silva 2004). A temperatura da água acompanhou a sazonalidade climática da região, com menores valores em jun $/ 2009\left(15,6^{\circ} \mathrm{C}\right.$ em S1 e $14,2^{\circ} \mathrm{C}$ em S2) e maiores em jan $/ 2010\left(33,0^{\circ} \mathrm{C}\right.$ em S1 e $24,3^{\circ} \mathrm{C}$ em S2).

As concentrações das espécies químicas dissolvidas $\left(\mathrm{Na}^{+}, \mathrm{K}^{+}, \mathrm{Ca}^{2+}, \mathrm{Mg}^{2+}\right.$ e $\left.\mathrm{SiO}_{2}\right)$ e do TDS relacionaram-se inversamente com a vazão, indicando um comportamento de diluição fluvial com o aumento da vazão (Figura 3), como observado para a maioria dos rios do mundo (Berner \& Berner 1996). As relações concentração $v s$ vazão permitiram o ajuste de modelos de potência $\left(C=a Q^{b}\right)$ altamente significativos $(\mathrm{p}<0,01 \%)$. Analisando o valor do expoente $b$ e relacionando-o à origem dos aportes, difuso ou pontual (Fernandes et al. 2017), verificou-se em $\mathrm{S} 1$ que $\mathrm{K}^{+}, \mathrm{Ca}^{2+}$ e $\mathrm{Mg}^{2+}$ relacionaram-se a aportes difusos $(b>-0,40)$ e $\mathrm{Na}^{+}$a aportes pontuais $(b<-0,60)$, enquanto que $\mathrm{SiO}_{2}$ e TDS tiveram origem associada a uma mistura de fontes, pontuais e difusas $(-0,40<b<-$ $0,60)$. Já em $\mathrm{S} 2$ todas as espécies químicas dissolvidas analisadas e o TDS relacionaram-se a aportes difusos $(b>-0,40)$.

A relação concentração de TSS vs vazão também permitiu o ajuste de um modelo de potência significativo $(\mathrm{p}<0,05 \%)$ para os dois pontos de amostragem. Para a maioria dos rios do mundo o expoente $b$ apresenta-se positivo, com valores entre 1 e 2 , indicando o aumento da concentração de sedimentos em suspensão em função do aumento da vazão (Probst 1986). No presente estudo os valores de $b$ mostraram-se inferiores a $1 \mathrm{em}$ ambos os pontos de amostragem, indicando que a carga de TSS também é influenciada pela precipitação, importante agente nos processos erosivos que proporciona a perda de solo e o carreamento de materiais aos corpos de água pelo escoamento superficial. Esta influência ficou evidenciada nas amostragens de nov/2009 e $\mathrm{mar} / 2010$ no ponto $\mathrm{S} 1$, onde as maiores concentrações de TSS $(145,00$ e $178 \mathrm{mg} / \mathrm{L}$, respectivamente) foram observadas após a ocorrência de eventos de chuva de 13,45 e 27,50 $\mathrm{mm}$, respectivamente, registrados pela estação pluviométrica E4-019 Iperó (DAEE 2010), enquanto que para a maior vazão registrada, $366,47 \mathrm{~m}^{3} / \mathrm{s}$ em jan/2010, a concentração de TSS foi de $101,50 \mathrm{mg} / \mathrm{L}$. No ponto S2 pode-se destacar a maior concentração de TSS $(28,17 \mathrm{mg} / \mathrm{L})$ na amostragem de nov/2009, onde a vazão foi de $26,51 \mathrm{~m}^{3} / \mathrm{s}$, enquanto que para a maior vazão, $57,24 \mathrm{~m}^{3} / \mathrm{s}(\mathrm{jan} / 2010)$ a concentração de TSS foi de $25,00 \mathrm{mg} / \mathrm{L}$, indicando que a carga de fluvial TSS está sujeita aos eventos de chuva ao longo de toda a bacia de drenagem.

\subsection{FLUXOS FLUVIAIS DE TSS E CARGA DISSOLVIDA}

Os fluxos fluviais de TSS e da carga dissolvida foram calculados para os pontos S1 e S2 utilizando a Equação 2. A princípio estes resultados permitiriam avaliar o grau de degradação física e de intemperismo químico que ocorrem na bacia do Rio Sorocaba. Entretanto, esses fluxos fluviais integram as contribuições dos processos naturais de intemperismo físico $\mathrm{e}$ químico que ocorrem na bacia de drenagem, dos aportes atmosféricos e, em certas regiões, dos aportes antrópicos associados à poluição industrial, agrícola e/ou doméstica, que chegam ao rio de forma pontual ou difusa. Assim, no presente trabalho, a carga de TSS foi corrigida da contribuição dos aportes antrópicos e as cargas de $\mathrm{SiO}_{2}, \mathrm{Na}^{+}, \mathrm{K}^{+}, \mathrm{Ca}^{2+}$ e $\mathrm{Mg}^{2+}$ dissolvidos foram corrigidas das contribuições dos aportes atmosféricos e antrópicos, como já descrito para outras bacias de drenagem (Probst et al. 1994, Mortatti et al. 1997, Semhi et al. 2000, Bortoletto
Junior et al. 2002, Conceição \& Bonotto 2003 2004, Weijden et al. 2006, Mortatti et al. 2008, Conceição et al. 2010, Fernandes et al. 2016a 2016b), utilizando um modelo de balanço de massas (Equação 3). Os fluxos resultantes da variação da biomassa e derivados dos sítios de troca iônica em minerais argilosos não foram considerados nos cálculos da carga dissolvida, uma vez que apresentam contribuições insignificantes, próximas de "zero", segundo White \& Blum (1995).

$$
F_{W}=F_{\text {Total }}-F_{\text {Atm }}-F_{\text {Antrop }}
$$

onde $F_{W}$ é o fluxo natural proveniente dos processos de degradação física e de alteração de rochas, $F_{\text {Total }}$ o fluxo fluvial total, $F_{A t m}$ a contribuição dos aportes atmosféricos e $F_{\text {Antrop }}$ a contribuição dos aportes antrópicos, todos expressos em $\mathrm{kg} /\left(\mathrm{km}^{2}\right.$ a) . 

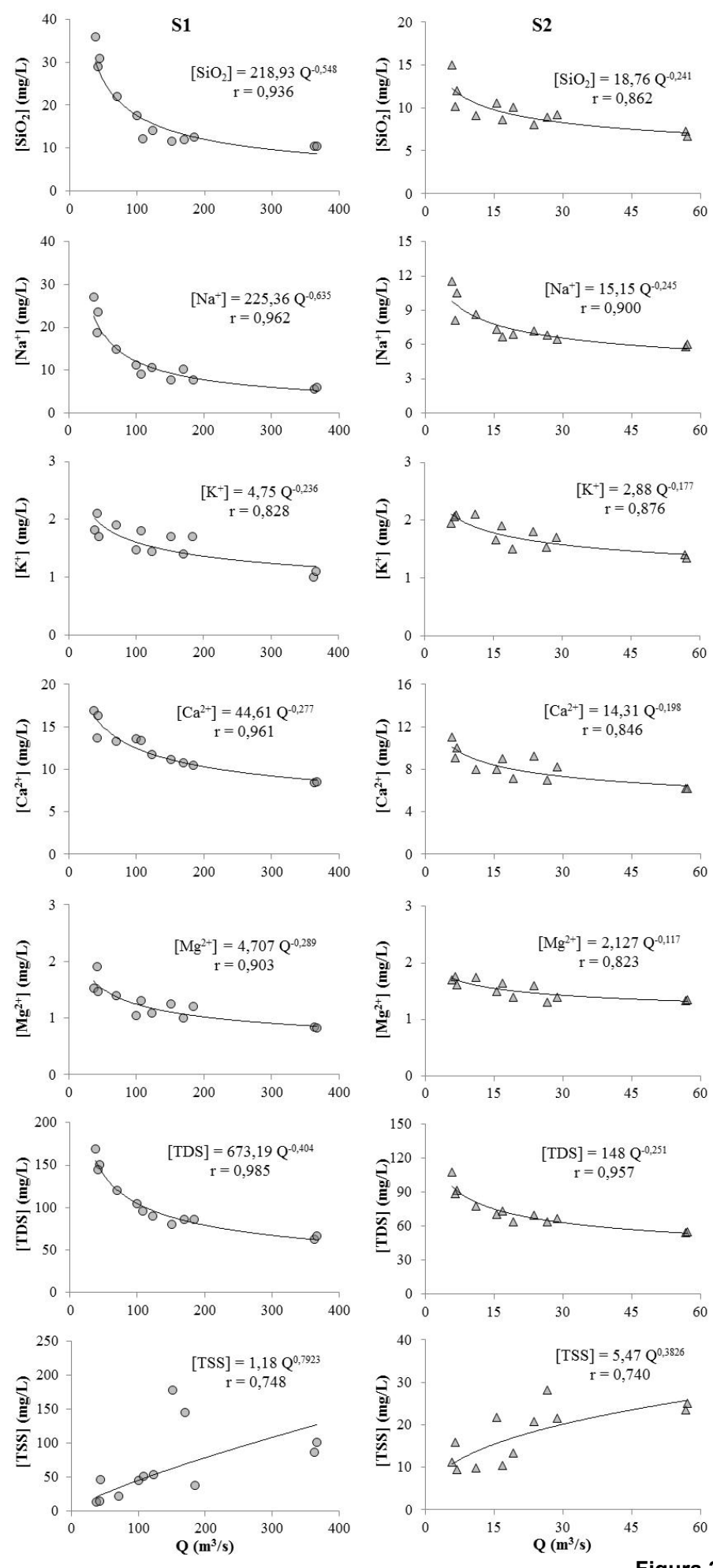

Relação concentração vs vazão para $\mathrm{SiO}_{2} \mathrm{Na}^{+}, \mathrm{K}^{+}, \mathrm{Ca}^{2+}, \mathrm{Mg}^{2+}$, Total de Sólidos Dissolvidos (TDS) e Total de Sólidos em Suspensão (TSS) com respectivos modelos de potência, para os pontos de amostragem S1 e S2 no Rio Sorocaba durante o período de estudo.

Para o TSS, a contribuição dos aportes antrópicos foi calculada considerando a carga per capita de sólidos em suspensão presentes no esgoto bruto sem tratamento $(0,022 \mathrm{~kg} /($ hab dia $))$ (Tchobanoglous 1991); a população total das áreas de contribuição dos pontos de amostragem, i.e. 1.212.376 e 104.214 habitantes em S1 e S2, respectivamente (IBGE 2010); e os percentuais de tratamento de esgoto de $25 \%$ em S1 e $17,5 \%$ em S2 (IPT 2006). Para a carga dissolvida transportada pelo Rio Sorocaba, a contribuição dos aportes atmosféricos em S1 e $\mathrm{S} 2$ foi representada pelo transporte pluvial específico de solutos, produto entre precipitação total no 
período de estudo (2101 mm - DAEE 2010) e a concentração média normalizada pela precipitação de $\mathrm{Na}^{+}(0,19 \mathrm{mg} / \mathrm{L}), \mathrm{K}^{+}(0,13 \mathrm{mg} / \mathrm{L}), \mathrm{Ca}^{2+}(1,42$ $\mathrm{mg} / \mathrm{L})$ e $\mathrm{Mg}^{2+}(0,09 \mathrm{mg} / \mathrm{L}$ ) (Fernandes 2012). Não houve correção para $\mathrm{o} \mathrm{SiO}_{2}$, uma vez que as entradas atmosféricas de sílica dissolvida são mínimas (White \& Blum 1995). Já a contribuição dos aportes antrópicos correspondeu ao produto entre os valores per capita das espécies químicas dissolvidas de interesse presentes nos efluentes domésticos brutos lançados sem tratamento prévio nos corpos de água $(\mathrm{g} /($ hab dia $))$ estabelecidos na bacia do Médio Tietê $\left(\mathrm{SiO}_{2}=0,84, \mathrm{Na}^{+}=13,10\right.$, $\mathrm{K}^{+}=2,60, \mathrm{Ca}^{2+}=7,50 \mathrm{e} \mathrm{Mg}^{2+}=1,30$ - Mortatti et al. 2008, Mortatti et al. 2012) e a população total das áreas de contribuição de S1 e S2. A Tabela 2 sintetiza os fluxos obtidos.

Tabela 2. Fluxo fluvial total $\left(F_{\text {Total }}\right)$, contribuições dos aportes atmosféricos $\left(F_{\text {Atm }}\right)$ e antrópicos $\left(F_{\text {Antrop }}\right)$ e o fluxo natural proveniente dos processos de degradação física e de alteração de rochas $\left(F_{W}\right)$ para o total de sólidos em suspensão (TSS), total de sólidos dissolvidos (TDS) e das espécies químicas dissolvidas no Rio Sorocaba, em termos de fluxo específico e percentagem do transporte fluvial total, para os pontos S1 e S2.

\begin{tabular}{|c|c|c|c|c|c|c|c|}
\hline \multicolumn{8}{|c|}{ S1 } \\
\hline & \multirow{2}{*}{$\begin{array}{c}\mathbf{F}_{\text {Total }} \\
\mathrm{kg} /\left(\mathrm{km}^{2} \text { a) }\right.\end{array}$} & \multicolumn{2}{|c|}{$\mathbf{F}_{\text {Atm }}$} & \multicolumn{2}{|c|}{$F_{\text {Antrop }}$} & \multicolumn{2}{|c|}{$\mathbf{F}_{\mathbf{W}}$} \\
\hline & & $\mathrm{kg} /\left(\mathrm{km}^{2} \mathrm{a}\right)$ & $\%$ & $\mathrm{~kg} /\left(\mathrm{km}^{2}\right.$ a $)$ & $\%$ & $\mathrm{~kg} /\left(\mathrm{km}^{2} \mathrm{a}\right)$ & $\%$ \\
\hline TSS & 74264,87 & - & - & 1524,33 & 2,05 & 72740,54 & 97,95 \\
\hline TDS & 74428,28 & 10336,16 & 13,89 & 7301,66 & 9,81 & 56790,46 & 76,30 \\
\hline $\mathrm{SiO}_{2}$ & 11939,16 & - & - & 70,55 & 0,59 & 11868,61 & 99,41 \\
\hline $\mathrm{Na}^{+}$ & 7927,75 & 320,30 & 4,04 & 1100,20 & 13,88 & 6507,25 & 82,08 \\
\hline $\mathbf{K}^{+}$ & 1226,05 & 215,90 & 17,61 & 218,36 & 17,81 & 791,78 & 64,58 \\
\hline $\mathrm{Ca}^{2+}$ & 9331,01 & 3121,69 & 33,45 & 629,89 & 6,75 & 5579,44 & 59,79 \\
\hline $\mathrm{Mg}^{2+}$ & 929,17 & 99,64 & 10,72 & 109,18 & 11,75 & 720,35 & 77,53 \\
\hline \multicolumn{8}{|c|}{ S2 } \\
\hline & $\mathbf{F}_{\text {Total }}$ & $\mathbf{F}_{\text {Atm }}$ & & $\mathbf{F}_{\text {Antr }}$ & & $\mathbf{F}_{\mathbf{W}}$ & \\
\hline & $\mathrm{kg} /\left(\mathrm{km}^{2} \mathrm{a}\right)$ & $\mathrm{kg} /\left(\mathrm{km}^{2} \mathrm{a}\right)$ & $\%$ & $\mathrm{~kg} /\left(\mathrm{km}^{2} \mathrm{a}\right)$ & $\%$ & $\mathrm{~kg} /\left(\mathrm{km}^{2} \mathrm{a}\right)$ & $\%$ \\
\hline TSS & 19821,37 & - & - & 1011,55 & 5,10 & 18809,82 & 94,90 \\
\hline TDS & 62716,84 & 10336,16 & 16,48 & 5329,95 & 8,50 & 47050,74 & 75,02 \\
\hline $\mathrm{SiO}_{2}$ & 8963,63 & - & - & 51,50 & 0,57 & 8912,13 & 99,43 \\
\hline $\mathrm{Na}^{+}$ & 6504,15 & 320,30 & 4,92 & 803,11 & 12,35 & 5380,74 & 82,73 \\
\hline $\mathbf{K}^{+}$ & 1689,38 & 215,90 & 12,78 & 159,40 & 9,44 & 1314,08 & 77,78 \\
\hline $\mathrm{Ca}^{2+}$ & 7858,62 & 3121,69 & 39,72 & 459,80 & 5,85 & 4277,13 & 54,43 \\
\hline $\mathrm{Mg}^{2+}$ & 465,97 & 99,64 & 21,38 & 79,70 & 17,10 & 286,62 & 61,51 \\
\hline
\end{tabular}

As contribuições antrópicas de TSS foram de $1524,33 \mathrm{~kg} /\left(\mathrm{km}^{2}\right.$ a) em S1 e de $1011,55 \mathrm{~kg} /\left(\mathrm{km}^{2}\right.$ a) em S2, representando $2,05 \%$ e $5,10 \%$ dos respectivos $\mathrm{F}_{\text {Total }}$ de TSS. Para o TDS a contribuição dos aportes atmosféricos foi de $10336,16 \mathrm{~kg} /\left(\mathrm{km}^{2}\right.$ a) em S1 e S2, representando $13,89 \%$ e $16,48 \%$ dos respectivos $\mathrm{F}_{\text {Total }}$ de TDS, enquanto que as contribuições antrópicas representaram 9,81\% em S1 e 8,50\% em S2 do $\mathrm{F}_{\text {Total }}$ de TDS. Dentre as espécies químicas dissolvidas, as maiores contribuições dos aportes atmosféricos em ambos os pontos de amostragem foram de $\mathrm{Ca}^{2+}$, superior a $33 \%$ do total de $\mathrm{Ca}^{2+}$ presente no rio. Esse predomínio nas águas de chuva da bacia do Rio Sorocaba pode estar associados à dissolução de $\mathrm{CaCO}_{3}$ derivado de material particulado em suspensão na atmosfera, oriundos da correção do solo e adubação de áreas agrícolas, queima de cana-de-açúcar, mineração de calcário dolomítico e fabricação de cimento nos municípios de Sorocaba e Votorantim e à queima de combustíveis fósseis por veículos e atividades industriais ao longo da bacia de drenagem, como já relatado em outros estudos (Conceição \& Bonotto 2004, Sardinha et al. 2010, Conceição et al. 2013, Fernandes et al. 2016a).

\subsection{REMOÇÃO DE SOLOS E INTEMPERISMO QUÍMICO}

A remoção de solos está associada à redução da espessura do solo e rochas pelo desagregamento físico de partículas sólidas que são transportadas pelo escoamento superficial até os corpos de água (Probst 1992). A taxa de remoção de solos de uma bacia de drenagem $\left(\mathrm{W}_{\mathrm{M}}\right.$, em $\mathrm{m} / \mathrm{Ma}$ ) pode ser expresso em função do transporte específico de TSS $\left(F_{T S S}, \mathrm{em} \mathrm{t} / \mathrm{km}^{2} / \mathrm{a}\right)$ e da densidade média dos solos da região $(d$, em $\mathrm{g} / \mathrm{m}^{3}$ ) (Mortatti et al. 1997, Boeglin \& Probst 1998). Utilizando os $F_{W}$ de TSS obtidos para S1 e S2 (Tabela 2) e a densidade média dos solos da bacia do rio Sorocaba, $1,47 \mathrm{~g} / \mathrm{cm}^{-3}$ (BRASIL 1983, Fernandes 2012), a taxa de remoção de solos em S1 correspondeu a 49,5 m/Ma, valor considerado como a remoção de solos da bacia do Rio Sorocaba, enquanto que em S2 a taxa foi de $12,8 \mathrm{~m} / \mathrm{Ma}$, indicando um invremento de 
quase quatro vezes da região das nascentes para a foz. Essa diferença pode ser associada, em maior ou menor grau, aos processos de uso e ocupação do solo ao longo da bacia de drenagem, destacando-se o manejo de solos agricultáveis na Depressão Periférica, onde os processos erosivos são mais intensos do que em áreas naturais, mais presentes na região das nascentes.

Os processos de intemperismo químico tendem a aprofundar o solo em detrimento das rochas através da dissolução ou hidrólise dos minerais primários das rochas, liberando em solução os elementos que são lixiviados pela água de drenagem, podendo ser considerados como uma forma de dissolução incongruente dos minerais primários por uma solução de ataque que resulta em minerais secundários mais lixiviados, ou decorrente da hidrólise parcial da rocha mãe, com parte do $\mathrm{SiO}_{2}$ permanecendo no perfil de alteração e $\mathrm{Na}, \mathrm{Ca}, \mathrm{K}$ e $\mathrm{Mg}$ sendo eliminados em solução. Esses processos são fortemente influenciados pela natureza dos minerais primários, clima, influências da biosfera, hidrodinâmica etc. (Summerfield 1991, Probst 1992).

$\mathrm{O}$ intemperismo químico pode ser estimado em termos de fluxo, considerando o transporte fluvial corrigido das espécies químicas oriundas do processo de alteração de rochas (Equação 3). No presente estudo correspondeu a um fluxo de 25,5 $\mathrm{t} / \mathrm{km}^{2} / \mathrm{a}$ em S1 e de $20,2 \quad \mathrm{t} / \mathrm{km}^{2} / \mathrm{a}$ em S2, representando $34 \%$ e $32 \%$ do $F_{\text {Total }}$ de TDS no Rio Sorocaba nos respectivos pontos de amostragem. Esse processo intempérico também foi avaliado através da taxa de alteração química do perfil rochoso da bacia de drenagem $\left(\mathrm{W}_{\mathrm{Ch}}\right.$, em $\left.\mathrm{m} / \mathrm{Ma}\right)$, obtida a partir do fluxo de intemperismo químico (IQ) ponderado pela densidade média das rochas da bacia de drenagem (Equação 4). Considerando que a densidade média de rochas da bacia do Rio Sorocaba é de $2,65 \mathrm{~g} / \mathrm{cm}^{3}$ (BRASIL 1983), a taxa $W_{C h}$ em S1 correspondeu a 9,6 m/Ma e em S2 a $7,6 \mathrm{~m} / \mathrm{Ma}$.

$$
I Q=F_{W}\left(N a^{+}\right)+F_{W}\left(K^{+}\right)+F_{W}\left(\mathrm{Ca}^{2+}\right)+F_{W}\left(\mathrm{Mg}^{2+}\right)+F_{W}\left(\mathrm{SiO}_{2}\right)
$$

onde $I Q$ corresponde ao intemperismo químico e $F_{W}$ (ion) ao fluxo fluvial corrigido de $\mathrm{Na}^{+}, \mathrm{K}^{+}$, $\mathrm{Ca}^{2+}, \mathrm{Mg}^{2+}$ e $\mathrm{SiO}_{2}$, todos em $\mathrm{t} /\left(\mathrm{km}^{2} \mathrm{a}\right)$.

$\mathrm{O}$ balanço entre as taxas $\mathrm{W}_{\mathrm{M}}$ e $\mathrm{W}_{\mathrm{Ch}}$ indicou que a taxa de remoção de solos, na bacia do Rio Sorocaba junto à foz (S1), foi 5,2 vezes maior que a taxa de alteração química, em consonância com o balanço global geralmente aceito para bacias de drenagem (Lasaga et al. 1994). Entretanto, no balanço entre as taxas verificadas em S2, a taxa de remoção de solos correspondeu a 1,7 vezes o intemperismo químico, o que pode estar associado à melhor conservação dos solos, tanto em áreas agrícolas quanto de remanescentes de vegetação natural, que favorecem a diminuição dos processos erosivos superficiais na área de contribuição.

O processo de alteração de rochas predominante na bacia do Rio Sorocaba pode ser avaliado usando o índice $\mathrm{R}_{\mathrm{E}}$ proposto por Tardy (1971) e modificado por Boeglin \& Probst (1998), expresso pela razão molar das espécies químicas dissolvidas nas águas superficiais, sílica e os cátions resultantes da alteração de rochas, onde os coeficientes utilizados dependem dos principais minerais primários do substrato rochoso e correspondem a uma média granítica com feldspato e mica, incluindo o $\mathrm{Mg}$ de minerais silicatados, como os anfibolitos (Equação 5). Assumindo que o índice $\mathrm{R}_{\mathrm{E}}$ equivale à razão molecular $\mathrm{SiO}_{2} / \mathrm{Al}_{2} \mathrm{O}_{3}$ da neoformação de minerais secundários no perfil do solo (Tardy 1971), o processo de intemperismo pode ser caracterizado segundo a classificação de Pedro (1966), i.e., para $R_{E}=0$ somente alumínio e ferro são fixados sob a forma de hidróxidos insolúveis, processo conhecido por alitização, com domínio de estabilidade da gibsita; quando $\mathrm{R}_{\mathrm{E}}=2$, o processo de alteração é a monossialitização, com domínio de estabilidade da caulinita; e, para $\mathrm{R}_{\mathrm{E}}=$ 4, o mecanismo predominante é o da bissialitização, originando minerais $2: 1$, como por exemplo, a montmorilonita. Os valores calculados de $R_{E}$ para $S 1$ e para $S 2$ foram de 2,6 e 2,1, respectivamente, indicando tendência do domínio de estabilidade da caulinita, ou seja, de um processo de monossialitização.

$$
R_{E}=\frac{3 K+3 \mathrm{Na}+2 \mathrm{Ca}+1,25 \mathrm{Mg}-\mathrm{SiO}_{2}}{0,5 \mathrm{~K}+0,5 \mathrm{Na} \mathrm{Ca}+0,75 \mathrm{Mg}}
$$

\subsection{MODELAGEM DO CONTROLO CLIMÁTICO NAS TAXAS DE REMOÇÃO DE SOLOS E DE INTEMPERISMO QUÍMICO}

Além da litologia, as taxas de intemperismo apresentam uma estreita relação com os aspectos climáticos de uma área de drenagem (Meybeck 1987, Gaillardet et al. 1999; Oliva et al. 2003). 
Gaillardet et al. (1999), ao revisarem trabalhos envolvendo 60 grandes rios do mundo, propuseram que o escoamento é o segundo parâmetro mais importante a controlar o intemperismo químico. Já Harrison (2000) destaca a precipitação e a topografia como fatores importantes que controlam a erosão mecânica. Dada a importância do escoamento no controle das taxas de intemperismo e a correlação significante entre precipitação e vazão (Figura 1B), a influência dos aspectos climáticos nos fluxos dos sólidos totais em suspensão (TSS) e de intemperismo químico $(I Q)$, bem como nas taxas de remoção de solos $\left(W_{M}\right)$ e de intemperismo químico das rochas $\left(W_{C h}\right)$ na bacia do Rio Sorocaba foi avaliada com a criação de 12 cenários baseados na variação das vazões ao longo do período de estudo, associando a cada um deles as respectivas concentrações de TSS, TDS, $\mathrm{SiO}_{2}$ e cátions dissolvidos (Tabela 1). Os valores observados a cada coleta em cada ponto de amostragem foram considerados como médias anuais. Para a correção dos aportes antrópicos assumiu-se as contribuições obtidas no período de estudo, considerando que a população e as cargas antrópicas não se alterariam. Já para os aportes atmosféricos, as contribuições foram calculadas a partir de dados mensais de concentração média normalizada pela precipitação e a anualização da precipitação média mensal observada para o período de 1959-2008 (DAEE 2010), i.e., junho $(\mathrm{C} 1$ e $\mathrm{C} 12)=453 \mathrm{~mm}$, julho $(\mathrm{C} 2)=416 \mathrm{~mm}$, agosto $(\mathrm{C} 3)=384 \mathrm{~mm}$, setembro $(\mathrm{C} 4)=801 \mathrm{~mm}$, novembro $(\mathrm{C} 5)=1431 \mathrm{~mm}$, dezembro $(\mathrm{C} 6)=$ $2105 \mathrm{~mm}$, janeiro $(\mathrm{C} 7)=2579 \mathrm{~mm}$, fevereiro (C8) $=2041 \mathrm{~mm}$, março $(\mathrm{C} 9)=1498 \mathrm{~mm}$, abril $(\mathrm{C} 10)$ $=732 \mathrm{~mm}$, maio $(\mathrm{C} 11)=826 \mathrm{~mm}$.

A Figura 4 ilustra os resultados obtidos para cada cenário e os valores deste estudo, para os pontos de amostragem S1 e S2. Os cenários relacionados ao clima mais quente e úmido ( 5 a 9) apresentaram fluxos de TSS e IQ maiores que os observados para o período de estudo em ambas as estações de amostragem, com exceção do fluxo de TSS no cenário 8 , que se mostrou abaixo do esperado. Essa situação pode ser explicada pelos dados utilizados no cálculo desse cenário, uma vez que a amostragem foi realizada no final do mês de referência e os eventos de chuva se concentraram na primeira quinzena do mesmo mês, influenciando na carga de sólidos em suspensão presentes no rio. Para os demais cenários, 1 a 4 e 10 a 12, que caracterizam clima mais seco e temperatura mais amena, os fluxos de TSS e IQ se mostraram menos intensos e abaixo do observado no período estudado.
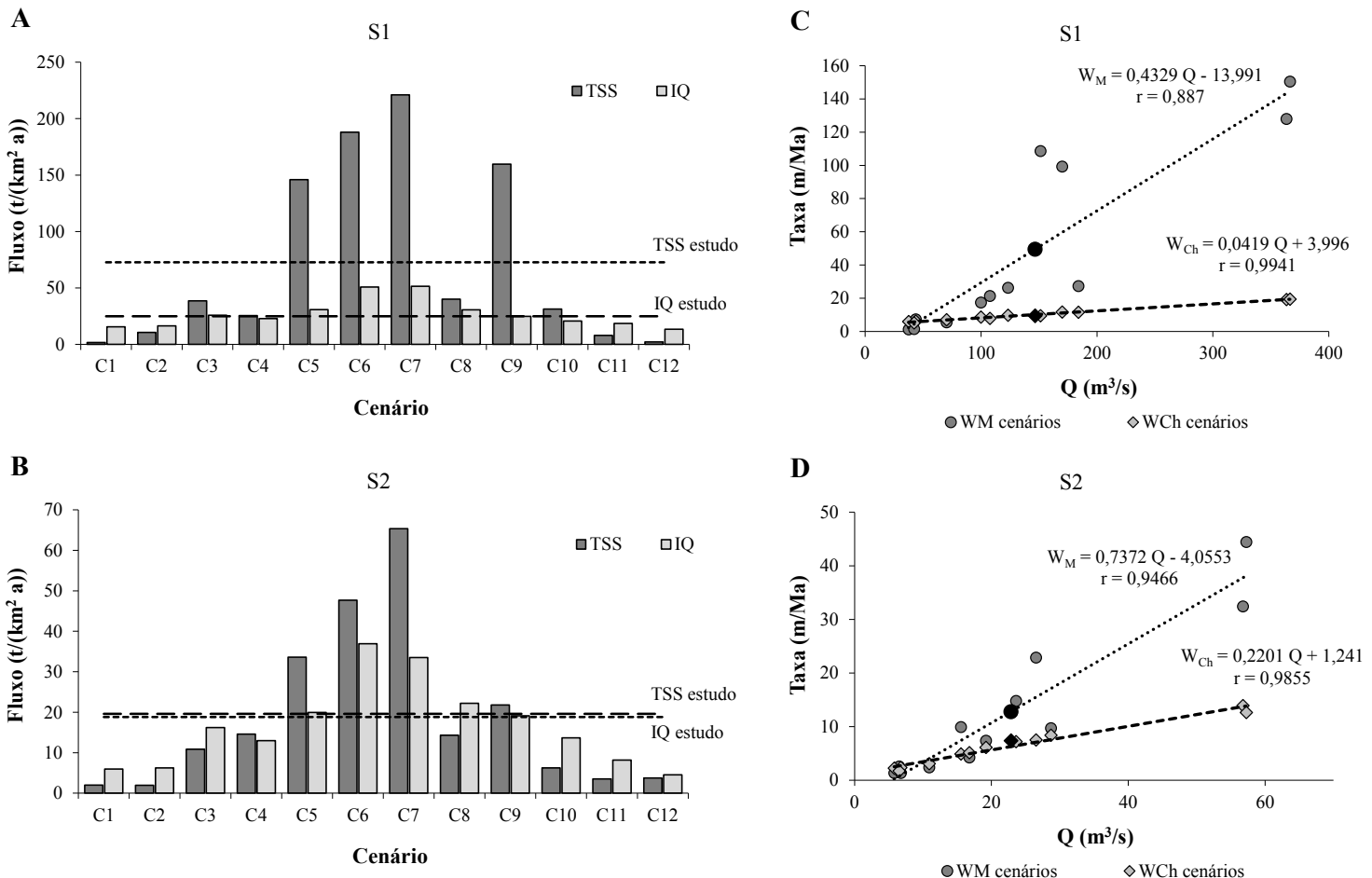

Figura 4

Cenários e resultados do presente estudo para o fluxo anual de sólidos totais em suspensão (TSS) e de intemperismo químico (IQ); e das taxas de remoção de solos $\left(W_{M}\right)$ e de intemperismo químico de rochas $\left(W_{C h}\right)$, para os pontos de amostragem S1 (A e C) e S2 (B e D) na bacia do Rio Sorocaba. 
As taxas de remoção de solos $\left(\mathrm{W}_{\mathrm{M}}\right)$ e de intemperismo químico de rochas $\left(\mathrm{W}_{\mathrm{Ch}}\right)$ para os cenários propostos espelharam a mesma influência em função do clima em ambos os pontos de amostragem (Figura 4C e 4D). Para os cenários de baixas vazões, relacionados a uma situação onde a precipitação também seria menor, as taxas $\mathrm{W}_{\mathrm{M}}$ e $\mathrm{W}_{\mathrm{Ch}}$ se mostraram próximas, com os processos de intemperismo de rochas mais intensos que os de remoção de solos. Os coeficientes angulares positivos observados nos modelos de regressão linear para $\mathrm{W}_{\mathrm{M}} \mathrm{e} \mathrm{W}_{\mathrm{Ch}}$ indicaram o crescimento das taxas em função do aumento da vazão nos dois pontos de amostragem, sendo que para o limite máximo de vazão em S1 a taxa $\mathrm{W}_{\mathrm{M}}$ seria cerca de 10 vezes mais acentuada que a taxa $\mathrm{W}_{\mathrm{Ch}}$, enquanto que em $\mathrm{S} 2 \mathrm{o}$ incremento seria de cerca de 3 vezes. A intersecção das curvas de regressão linear de $\mathrm{W}_{\mathrm{M}}$ e $\mathrm{W}_{\mathrm{Ch}}$ em cada ponto de amostragem permitiram estabelecer o cenário hipotético onde as taxas estariam em equilíbrio, que em S1 seria de 6,26 m/Ma e em S2 de 4,09 $\mathrm{m} / \mathrm{Ma}$, relacionadas a vazões de $46,77 \mathrm{~m}^{3} / \mathrm{s}$ e $11,04 \mathrm{~m}^{3} / \mathrm{s}$, respectivamente.

Os cenários confirmam a premissa de que em situação de clima quente e úmido, i.e., maior volume precipitado, os processos de intemperismo que envolvem a remoção de solos e o intemperismo químico das rochas seriam favorecidas, resultando em maiores fluxos e taxas; e que em condição contrária, de clima mais ameno e seco (menor volume precipitado), essas reações seriam mais moderadas, como também observado por Spatti Junior et al. (2014).

$O$ processo de intemperismo de rochas expresso pelo índice $\mathrm{R}_{\mathrm{E}}$ calculado para os cenários (Figura 5) indicou a manutenção dos domínios observados no período de estudo, apesar dos diferentes fluxos de IQ e taxas de $\mathrm{W}_{\mathrm{Ch}}$ observados para os cenários propostos. Tardy (1971) explica que a composição química das águas é sensível à variação climática e reflete a evolução do intemperismo no momento da amostragem, e que a sazonalidade de temperatura e a precipitação anual podem interferir e modificar a dinâmica geoquímica do intemperismo, mas não são mais importantes do que a concentração das soluções de solo que determinam a natureza das neoformações. Assim, a variação observada no índice $\mathrm{R}_{\mathrm{E}}$ dos cenários propostos justifica-se, sem modificação de domínio no processo de intemperismo de rochas, pois a variação sazonal anual do período de estudo utilizada para modelar os cenários não representa uma variação climática com duração suficiente e necessária para alterar significativamente as neoformações existentes atualmente.

S1

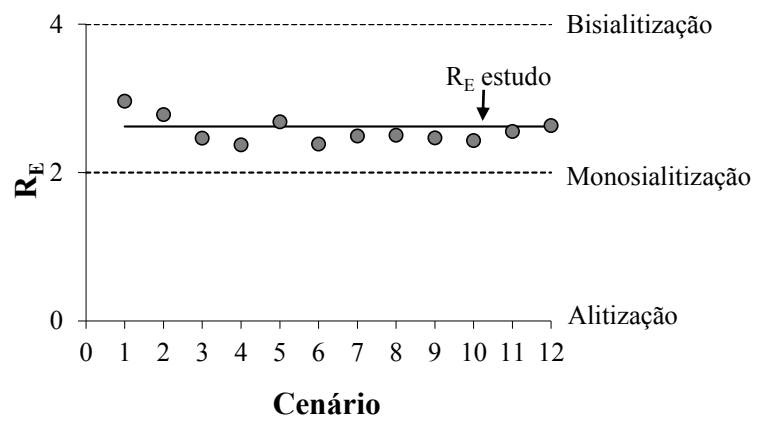

S2

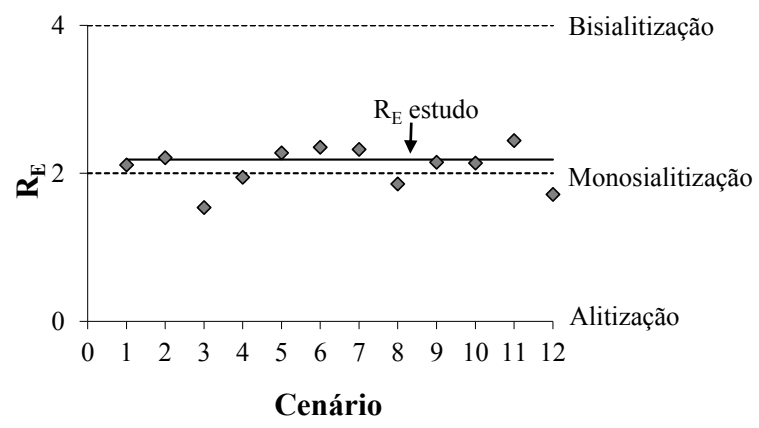

Figura 5

Índice $\mathrm{R}_{\mathrm{E}}$ para os 12 cenários propostos e o obtido no presente estudo por ponto de amostragem na bacia do Rio Sorocaba. 


\section{CONCLUSÕES}

Foi possível avaliar os fluxos e taxas relacionados aos processos de remoção de solos e de intemperismo químico das rochas na bacia do Rio Sorocaba por meio da caracterização do TSS e da carga dissolvida de cátions, $\mathrm{SiO}_{2}$ e TDS e seus respectivos fluxos fluviais, após a correção dos aportes atmosféricos e antrópicos. Além disso, verificou-se o comportamento desses fluxos e taxas em 12 cenários relacionados a possíveis alterações climáticas considerando a sazonalidade da vazão ao longo do ciclo hidrológico de jun/2009 a jun/2010. Os fluxos fluviais corrigidos dos aportes atmosféricos e antrópicos calculados para os pontos de amostragem $\mathrm{S} 1 \quad\left(\mathrm{~F}_{\mathrm{TSS}}=\right.$ $72740,54 \mathrm{~kg} / \mathrm{km}^{2} / \mathrm{a}$ e $\left.\mathrm{F}_{\mathrm{TDS}}=72740,54 \mathrm{~kg} / \mathrm{km}^{2} / \mathrm{a}\right)$ e $\mathrm{S} 2\left(\mathrm{~F}_{\mathrm{TSS}}=18809,82 \mathrm{~kg} / \mathrm{km}^{2} / \mathrm{a}\right.$ e $\mathrm{F}_{\mathrm{TDS}}=72740,54$ $\mathrm{kg} / \mathrm{km}^{2} / \mathrm{a}$ ) permitiram determinar as taxas de remoção de solos $\left(\mathrm{W}_{\mathrm{M}}\right)$ e de intemperismo

\section{AGRADECIMENTOS}

Os autores agradecem à FAPESP (Processos $n^{\circ}$ 08/57104-4 e 08/09369-9) e ao CNPq (Processo ${ }^{\circ}$ 134.169/2009-3) para o apoio financeiro; ao CENA/USP e à UNESP que possibilitaram a

\section{REFERÊNCIAS BIBLIOGRÁFICAS}

APHA - American Public Health Association 1999. Standard Methods for the Examination of Water and Wastewater. 20. ed. APHA, Washington D.C., 541 pp.

Barth T.F.W. 1961. Abundance of the elements, areal averages and geochemical cycles. Geochim. Cosmochim. Acta, 23:1-8.

Berner E.K., Berner R.A. 1996. Global environment water, air, and geochemical cycles. Prentice-Hall, Englewood Cliffs, New Jersey, 376 pp.

Boeglin J.I., Probst J.L. 1998. Physical and chemical weathering rates and $\mathrm{CO}_{2}$ consumption in a tropical lateritic environment: the upper Niger basin. Chem. Geol., 148:137-156.

Bortoletto Junior M.J., Mortatti J., Probst J.L. 2002. Erosão química na bacia hidrográfica do rio Corumbataí (SP). Geochim. Bras., 16(1):99-111.

BRASIL, Ministério das Minas e Energia. 1983. Projeto RADAMBRASIL. Folhas 23/24. Rio de Janeiro, Levantamento de Recursos Naturais, 32:27-247.

Conceição, F.T., Santos, C.M., Sardinha, D.S., Navarro, G.R.B., Godoy, L.H., 2015. Chemical weathering rate, denudation rate, and atmospheric and soil $\mathrm{CO}_{2}$ consumption of Paraná flood basalts in São Paulo State, Brazil. Geomorphology, 233, 41-51.

Conceição F.T., Antunes M.L.P., Angelucci V.A., Moruzzi R.B., Navarro G.R.B. 2013. Rainwater chemical composition and annual atmospheric químico das rochas $\left(\mathrm{W}_{\mathrm{Ch}}\right)$ na Bacia do Rio Sorocaba, ou seja, 49,5 e 9,6 m/Ma em S1 e de 12,8 e $7,6 \mathrm{~m} / \mathrm{Ma}$ em $\mathrm{S} 2$, respectivamente. O balanço entre estas taxas evidenciou uma maior remoção de solos em $\mathrm{S} 1\left(\mathrm{WM} \approx 5,2 \mathrm{~W}_{\mathrm{Ch}}\right)$, em comparação à $\mathrm{S} 2\left(\mathrm{WM} \approx 1,7 \mathrm{~W}_{\mathrm{Ch}}\right)$. $\mathrm{O}$ processo de intemperismo químico de rochas avaliado pelo índice $R_{E}$ indicou tendência para o domínio da monossialitização. Os cenários propostos corroboraram a influência do clima nos processos intempéricos, com predomínio dos processos de intemperismo químico das rochas nos cenários relacionados à condições climáticas de baixa pluviosidade e temperaturas mais amenas, e o predomínio dos processos de remoção dos solos em condições mais chuvosa e temperaturas mais elevadas.

realização e divulgação da pesquisa. A.M. Fernandes também agradece ao Programa de PósGraduação da Faculdade de Engenharia Civil da UNESP Bauru, pela bolsa de Pós-doutorado.

deposition in Sorocaba, (São Paulo State), Brazil. Rev. Bras. Geofísica, 31(1):5-15.

Conceição F.T., Bonotto D.M. 2003. Use of U-isotopes disequilibrium to evaluate the weathering rates and fertilizer derived uranium at São Paulo State, Brazil. Environ. Geol., 44(4):408-418.

Conceição F.T., Bonotto D.M. 2004. Weathering rates and anthropogenic influences in a sedimentary basin, São Paulo State, Brazil. Appl. Geochem., 19:575591.

Conceição F.T., Sardinha D.S., Souza A.D.G., Navarro G.R.B. 2010. Anthropogenic influences on annual flux of cations and anions at Meio Stream basin, São Paulo State, Brazil. Water Air Soil Pollut., 205(14):79-91.

DAEE - Departamento de Águas e Energia Elétrica, 2010. Banco de dados hidrológicos; 2010. Disponível em: http//www.hidrologia.daee.sp.gov.br/. Acessado em 3 set 2010.

Dionex Corporation. 2004. ICS-90 ion chromatography system operator's manual. California: Dionex Corporation. (Document n.031851, revision 4).

Dupré B., Dessert C., Oliva P., Goddéris Y., Viers J., François L., Millot R., Gaillardet J. 2003. Rivers, chemical weathering and Earth's climate. Compt. Rendus Geosci., 335:1141-1160. 
Edet A., Ukpong A., Nganje T. 2013. Hydrochemical studies of Cross River Basin (southeastern Nigeria) river system using cross plots, statistics and water quality index. Environ. Earth Sci., 70:3043-3056.

Fernandes A.M. 2012. Características hidrogeoquímicas da bacia de drenagem do rio Sorocaba, SP: processos erosivos mecânicos e químicos. Tese de Doutorado, Centro de Energia Nuclear na Agricultura, Universidade de São Paulo.

Fernandes A.M., Conceição F.T., Spatti Junior E.P., Sardinha D.S., Mortatti J. 2016a. Chemical weathering rates and atmospheric/soil $\mathrm{CO}_{2}$ consumption of igneous and metamorphic rocks under tropical climate in southeastern Brazil. Chem. Geol. 443:54-66.

Fernandes A.M., Conceição F.T., Spatti Junior E.P., Guedes Junior E., Sardinha D.S., Mortatti J. 2017. Avaliação dos fluxos das principais espécies químicas dissolvidas no Rio Sorocaba (SP). Geociências. 36(1):01-12.

Fernandes A.M., Hissler C., Conceição F.T., Spatti Junior E.P., Mortatti J. 2016b. Combined analysis of trace elements and isotopic composition of particulate organic matter in suspended sediment to assess their origin and flux in a tropical disturbed watershed. Environ. Pollut. 218:844-854.

Gaillardet J., Dupré B., Allègre C.J., Négrel P. 1997. Chemical and physical denudation in the Amazon river basin. Chem. Geol., 142:141-173.

Gaillardet J., Dupré B., Louvat P., Allègre C.J. 1999. Global silicate weathering and $\mathrm{CO}_{2}$ consumption rates deduced from the chemistry of large rivers. Chem. Geol., 159:3-30.

Gibbs R.J. 1970. Mechanisms controlling world river water chemistry. Science, 170:1088-1090.

Gurumurthy G.P., Balakrishna K., Riotte J., Braun J.J., Audry S., Shankar H.N.U., Manjunatha B.R. 2012. Controls on intense silicate weathering in a tropical river, southwestern India. Chem. Geol., 300-301:6169.

Harrison C.G.A. 2000. What factors control mechanical erosion rates? Int. J. Earth Sci., 88:752-763.

Hermes L.C., Silva A.S. 2004. Avaliação da qualidade das águas: manual prático. Brasília, Embrapa Informação Tecnológica, 55 pp.

IBGE - Instituto Brasileiro de Geografia e Estatística 2010. Dados do Censo 2010. Diário Oficial da União, Brasília, DF, 04 nov. 2010. Disponível em: $<$ http://www.ibge.gov.br/censo2010/dados_divulgad os/index.php?uf=35 $\geq$. Acessado em $3 \mathrm{dez} 2010$.

IPT - Instituto de Pesquisas Tecnológicas. 2006. Relatório Zero da Bacia do Sorocaba e Médio Tietê - Atualização 2005. São Paulo, Relatório Técnico n ${ }^{\circ}$ 80:401-205, $462 \mathrm{p}$.

Jenkins A., Peters N.E., Rhode A. 1994. Hydrology. In: B. Moldan \& J. Cerny (eds.) Biogeochemistry of small catchments: a tool for environmental research. Chichester: John Wiley \& Sons, 1994.

Laraque A., Moquet J.S., Alkattan R., Steiger J., Mora A., Adèle G., Castellanos B., Lagane C., Lopez J.L., Perez J., Rodriguez M., Rosales J. 2013. Seasonal variability of total dissolved fluxes and origin of major dissolved elements within a large tropical river: The Orinoco, Venezuela. J. S. Am. Earth Sci., 44:4-17.

Lasaga A.C., Soler J.M., Ganor J., Burch T.E., Nagy K.L. 1994. Chemical weathering rate laws and global geochemical cycles. Geochim. Cosmochim. Acta, 58(10):2361-2386.

Li S., Lu X.X., Bush R. 2014. Chemical weathering and $\mathrm{CO}_{2}$ consumption in the Lower Mekong River. Sci. Total Environ., 472:162-177.

Li S., Zhang Q. 2008. Geochemistry of the upper Han River basin, China, 1: Spatial distribution of major ion compositions and their controlling factors. Appl. Geochem., 23:3535-3544.

Martin J.M., Meybeck M. 1979. Elemental mass-balance of material carried by major world rivers. Mar. Chem., 7:173-206.

Meybeck M. 1987. Global geochemical weathering of surficial rocks estimated from river dissolved loads. Am. J. Sci., 287:401-428.

Meybeck M., Laroche L., Dürr H.H., Syvitski J.P.M. 2003. Global variability of daily total suspended solids and their fluxes in rivers. Glob. Planet. Change, 39:65-93.

Mortatti J., Probst J.L. 2003. Silicate rock weathering and atmospheric/soil $\mathrm{CO}_{2}$ uptake in the Amazon basin estimated from river water geochemistry: seasonal and spatial variations. Chem. Geol., 197:177-196.

Mortatti J., Probst J.L., Fernandes A.M., Mortatti B.C., Oliveira H. 2008. Influence of discharge on silicate weathering dynamics of the Tiete river basin: major cations and dissolved silica approach. Geochim. Bras., 22(1):15-26.

Mortatti J., Probst J.L., Ferreira J.R. 1992. Hydrological and geochemical characteristics of the Jamari and Jiparana river basin (Rondonia, Brazil). GeoJournal, 26(3):287-296.

Mortatti J., Vendramini D., Oliveira H. 2012. Avaliação da poluição doméstica fluvial na zona urbana do município de Piracicaba, SP, Brasil. Rev. Ambient. Água, 7(2):110-119.

Mortatti J., Victoria R.L., Tardy Y. 1997. Balanço de alteração e erosão química na bacia amazônica. Geochim. Bras., 11(1):2-13.

Oliva P., Viers J., Dupré B. 2003. Chemical weathering in granitic environments. Chem. Geol., 202:225-256.

Oliveira J.B., Camargo M.N., Rossi M., Calderano Filho B. 1999. Mapa pedológico do Estado de São Paulo: legenda expandida. Campinas: Instituto Agronômico; Rio de Janeiro: Embrapa-Solos, 64p.: mapa.

Paces T. 1986. Rate of chemical weathering in small drainage basins. In: S. Coleman \& D. Dethier (eds.) Rates of Chemical Weathering of Rocks and Minerals. Academic Press, p.: 531-550.

Pedro G. 1966. Essais sur la caractérisation géochimique des différents processus zonaux résultant de l'altération de roches superficielles (cycle aluminosillicique). C. R. Acad. Sci. Paris, 262:18211831.

Probst J.L. 1986. Dissolved and suspended matter transported by the Girou River (France): mechanical 
e chemical erosion rates in a calcareous molasse basin. Hydrol. Sci. J., 31:61-79.

Probst J.L. 1992. Géochimie et Hydrologie de l'Érosion Continentale. Mécanisms, Bilan Global Actuel et Fluctuations au Cours des 500 Derniers millions d'annés. Sci. Géol. Mém., 94 (161 p.).

Probst J.L., Mortatti J., Tardy Y. 1994. Carbon river fluxes and global weathering $\mathrm{CO}_{2}$ consumption in the Congo and Amazon river basins. Appl. Geochem., 9:1-13

Probst J.L., Nkounkou R.R., Krempp G., Bricquet J.P., Thiébaux J.P., Olivry J.C. 1992. Dissolved major elements exported by the Congo and the Ubangui rivers during the period 1987-1989. J. Hydrol., 135:237-257.

Ribani M., Bottoli C.B.G., Collins C.H., Jardim I.C.S.F., Melo L.F.C. 2004. Validação em métodos cromatográficos e eletroforéticos. Quim. Nova, 27(5):771-780.

Riebe C.S., Kirchner J.W., Finkel R.C. 2004. Erosional and climatic effects on long-term chemical weathering rates in granitic landscapes spanning diverse climate regimes. Earth Planet. Sci. Lett., 224:547-562.

Ross J.L.S. 1996. Geografia do Brasil. v. 3. EDUSP, São Paulo, 546 p.

Ross J.L.S., Moroz I.C. 1997. Mapa geomorfológico do Estado de São Paulo. São Paulo: Laboratório de Geomorfologia, Depto Geografia, FFLCH-USP, Laboratório de Cartografia Geotécnica - Geologia Aplicada - IPT, FAPESP. Mapas e Relatórios - SP.

Sardinha D.S., Bonotto D.M., Conceição F.T. 2010. Weathering rates at Alto Sorocaba basin, Brazil, using U-isotopes and major cations. Environ. Earth Sci., 61:1025-1036.
Semhi K., Suchet P.A., Clauer N., Probst J.L. 2000. Impact of nitrogen fertilizers on the natural weathering-erosion process and fluvial transport in the Garonne basin. Appl. Geochim., 15:865-878

Spatti Junior E.P., Conceição F.T., Guedes Junior E., Pinto S.A.F., Pereira L.H. 2014. Balanço entre intemperismo químico e remoção do solo na bacia do ribeirão Monjolo Grande, Ipeúna (SP), determinado por geoquímica fluvial. Rev. Bras. Geomorfol., 15(1):137-152.

Summerfield M.A. 1991. Global geomorphology. Harlow, England and New York: Longman and Wiley.

Tardy Y. 1971. Characterization of the principal weathering types by the geochemistry of waters from some european and african crystalline massifs. Chem. Geol., 7:253-271.

Tchobanoglous G. 1991. Wastewater engineering: treatment, disposal and reuse. Metcalf \& Eddy, Inc. 3rd edn. McGraw-Hill: Singapore

Velbel A.M., Price J.R. 2007. Solute geochemical massbalances and mineral weathering rates in small watersheds: Methodology, recent advances, and future directions. Appl. Geochem., 22(8):1682-1700.

Walling D.E., Fang D. 2003. Recent trends in the suspended sediment loads of the world's rivers. Glob. Planet. Change, 39:111-126.

Weijden H.V., Pacheco F.A.L. 2006. Hydrogeochemistry in the Vouga River basin (central Portugal): Pollution and chemical weathering. Appl. Geochem., 21(4):580-613.

White A.F., Blum A.E. 1995. Effects of climate on chemical weathering in watersheds. Geochem. Cosmochim. Acta, 59:1729-1747. 